\title{
Extramedullary Plasmacytoma of the breast in a patient with Multiple Myeloma
}

\author{
Stephen Vong ${ }^{1 *}$, Shannon Marisa Navarro ${ }^{1}$, Morgan Darrow ${ }^{2}$, Shadi Aminololama-Shakeri ${ }^{1}$ \\ 1. Department of Radiology, UC Davis Health, Sacramento, California, USA \\ 2. Department of Pathology and Laboratory Medicine, UC Davis Health, Sacramento, California, USA \\ * Correspondence: Stephen Vong MD, Department of Radiology, UC Davis Health. 4860 Y Street, Suite 3100. Sacramento California, \\ 95817, USA \\ (入sevong@ucdavis.edu)
}

Radiology Case. 2020 Dec; 14(12):14-23 :: $\quad$ DOI: $10.3941 /$ jrcr.v14i12.4110

\begin{abstract}
Extramedullary plasmacytoma of the breast is rare. It is important to recognize the imaging findings and include it as a differential consideration in multiple myeloma patients with a breast mass. A 74-year-old woman undergoing chemotherapy for relapsed multiple myeloma presented with a palpable mass in her right breast. A screening mammogram four months prior was unremarkable. She underwent a diagnostic right mammogram which showed two well-circumscribed hyperdense masses. An ultrasound of the right breast showed mixed echogenic masses with indistinct margins and increased vascularity. Ultrasound guided biopsy confirmed the presence of an extramedullary plasmacytoma. A follow-up whole body PET/CT demonstrated an FDG-avid right breast mass with extensive osseous metastases.
\end{abstract}

\section{CASE REPORT}

\section{CASE REPORT}

A 74-year-old woman undergoing chemotherapy for relapsing multiple myeloma (subtype IgG Lambda) presented to her medical oncologist with a new palpable right breast lump. A screening mammogram four months prior was interpreted as normal and given a BI-RADS Category 1 (negative) final assessment (Figure 1). Kappa free light chains were significantly decreased at $0.17 \mathrm{mg} / \mathrm{dL}$ (normal $0.33-$ $1.94 \mathrm{mg} / \mathrm{dL}$ ) and Lambda free light chains were significantly elevated at $197 \mathrm{mg} / \mathrm{dL}$ (normal $0.57-2.63 \mathrm{mg} / \mathrm{dL}$ ). Clinically, the patient had persistent whole-body aches, oral bleeding, and bone pain. The patient was then referred to the breast imaging service for further work-up. She underwent a diagnostic right mammogram which showed two well-circumscribed hyperdense masses - there were no suspicious calcifications, nipple retraction, skin thickening, or areas of architectural distortion (Figure 2). A same-day ultrasound demonstrated two mixed echogenic masses with ill-defined margins and increased vascularity (Figure 3). Primary differential considerations included plasmacytoma and primary breast cancer. Hematoma was initially considered as the patient was on anticoagulation for deep venous thrombosis prophylaxis. However, given the presence of vascularity, it was deemed unlikely. An infectious etiology (i.e., breast abscess) was also considered given the rapid increase in size over four months. This was thought to be unlikely with no clinical signs of infection and central rather than peripheral vascularity. A microscopic examination of an ultrasound guided biopsy yielded plasma cell neoplasm (Figure 5). A follow-up PET/CT 
showed a FDG-avid right breast mass with a standardized uptake value (SUV) maximum of $3.6 \mathrm{~g} / \mathrm{mL}$ and extensive osseous metastases - the breast mass was not present on PET/CT one year earlier (Figure 4).

\section{Treatment and Outcome:}

In the ensuing two months, the patient's clinical status deteriorated. Despite being on her fourth line of chemotherapy, her Lambda free light chain values increased rapidly. Palliative radiation therapy was started to assist with pain control. After multiple hospital admissions for refractory pain and altered mental status within the span of two weeks, the patient entered hospice care and passed away five days later.

\section{DISCUSSION}

\section{Etiology \& Demographics:}

Plasma cell dyscrasias include a spectrum of diseases with pathophysiology based on monoclonal proliferation of plasma cells. Plasmacytomas are tumors resulting from plasma cell dyscrasias and can occur as solitary lesions or in the setting of multiple myeloma. They can be found in osseous structures (solitary bone plasmacytomas) or the soft tissues (extramedullary plasmacytomas) [1]. In the setting of multiple myeloma, the incidence of extramedullary plasmacytomas range from $7-18 \%$, with $80 \%$ involving the upper aerodigestive tract [1]. Breast involvement is rare, with approximately 63 cases reported worldwide between 1928 to 2009 [2]. The study authors found an additional 20 published reports in the literature between 2009 to 2019, [3-22], with two retrospective institutional reviews $[15,16]$. Additionally, Surov et al. conducted a comprehensive review of prior case reports and patients at their institution between 1997-2009, finding that $15 \%$ of breast plasmacytomas were primary lesions while $85 \%$ involved multiple myeloma [23]. Thus, breast plasmacytomas can occur in the absence of multiple myeloma [14], in active multiple myeloma [18], and in relapsing multiple myeloma [20]. Notable reported cases include the involvement of breast implants [22] and diagnosis in a male patient [8]. Although the exact prevalence is unknown, Alsadi et al. (2017) conducted a retrospective review of cases in their institution spanning 22 years and discovered four cases of breast plasmacytomas [15]. Given that it is rarely encountered, it is important to recognize the various imaging findings of breast plasmacytomas on multiple modalities.

\section{Imaging Findings:}

Mammography: First line imaging involves mammography as patients often present with a palpable breast mass. In a thirteen-year single institution retrospective study, Surov et al. found that $83 \%$ of patients with plasmacytomas presented with breast lumps and $66 \%$ had a unilateral mass [23]. These high-density masses were ovoid or round with well-circumscribed margins $[10,13,18,20]$. One study noted a partial lucent halo sign [5]. There are no known reports of masses with spiculated margins or associated microcalcifications. Following mammography, palpable masses should be further evaluated with ultrasound.
Ultrasound (US): On US, plasmacytomas have been described to be oval or round, with margins that may be welldefined or indistinct, heterogenous to hypoechoic, and may include a hyperechoic rim [5]. Often, they have increased vascularity and posterior shadowing [13,18,20]. Given the ultrasound characteristics, plasmacytomas can be misdiagnosed as a primary breast cancer [23]. A biopsy should be performed to exclude primary breast carcinoma.

Computer Tomography $(C T)$ : Plasmacytomas discovered on $\mathrm{CT}$ are incidental as this is not considered a first-line breast imaging modality due to radiation exposure. Findings are nonspecific and include oval well-circumscribed masses with homogenous enhancement [10,20]. Such masses should be further evaluated with dedicated breast imaging modalities.

Magnetic Resonance Imaging (MRI): To date, there are only four known studies on the MRI findings of breast plasmacytomas $[9,13,24,25]$. In general, T1/T2 signal intensity has been variable, ranging from low $\mathrm{T} 1$ and intermediate $\mathrm{T} 2$ [9] to isointense T1 and high T2 signal intensity [13]. One study noted restricted diffusion [13]. Of the studies that performed dynamic contrast-enhanced MRI, both demonstrated homogenous enhancement with delayed washout kinetics [10,14].

Position Emission Tomography/Computer Tomography $(P E T / C T)$ : This modality is performed for staging and evaluation for progression of disease, with increased FDG avidity in plasmacytomas [13].

\section{Treatment \& Prognosis:}

Extramedullary plasmacytoma in the setting of multiple myeloma has a poor prognosis, with a median overall survival of less than 6 months for extramedullary relapse [26]. In a review of 226 relapsed multiple myeloma patients, Pour et al. found that overall survival was as low as four months for those with extramedullary myeloma infiltration separate from bone, compared to twelve months for those with an extramedullary mass adjacent to bone [27]. The specific prognosis for breast plasmacytomas is unknown. However, primary breast plasmacytomas have been shown to have a better prognosis than those associated with multiple myeloma [28].

The evolving treatment of multiple myeloma continues to be based on risk stratification. Therapies can include induction chemotherapy (proteasome inhibitors such as bortezomibbased triple regimens), autologous stem cell transplant, and maintenance chemotherapy (lenalidomide or bortezomib) [29]. First-line treatment for the associated plasmacytomas involves radiotherapy and possibly surgical excision. In more challenging areas, such as the head and neck, treatment often avoids excision due to disfigurement [29].

\section{Differential Diagnoses:}

The differential considerations for a hyperdense breast mass on mammography include hematoma, infection, fibroadenoma/phyllodes tumor, and primary breast cancer.

Hematoma: Clinical history is of the utmost importance when considering this diagnosis. Patients may have a history 
of a recent procedure, trauma, or use of anticoagulation medication. On mammography, these will appear as hyperdense lesions. On ultrasound, they range from anechoic to hypoechoic depending on acuity, have indistinct margins, and are avascular. On MRI, hematomas are acutely T1 hyperintense and become hypointense in the chronic setting. There is no significant contrast enhancement - a uniformly thin rim of enhancement $(\leq 4 \mathrm{~mm})$ can be seen in the postoperative setting.

Infection: The primary differential consideration is the formation of a breast abscess. Two types are noted in the literature. Puerperal abscess forms during the lactation period while non-puerperal abscess forms outside of the lactation period. Clinical history is vital as patients will present with erythema, skin swelling, and pain around the infected breast. On mammogram, findings are nonspecific but can include an irregular hyperdense mass, skin thickening, and diffuse edema. On ultrasound, there will be an ill-defined thick-walled hypoechoic fluid collection with internal debris and increased peripheral vascularity. On MRI, there will be a thick-walled fluid collection demonstrating avid rim enhancement on $\mathrm{T} 1$ post contrast images [30].

Fibroadenoma/Phyllodes Tumor: Fibroadenomas are common benign breast tumors while phyllodes tumors are rare. Both share similar features on imaging. Phyllodes tumors are frequently resected due to malignant potential. In evaluation of the two entities, Duman et al. found many similarities and some differences [31]. On mammography, fibroadenomas demonstrated benign features, such as oval shape and circumscribed margins. On ultrasound, fibroadenomas had oval shape, circumscribed margins, parallel orientation, hypoechogenicity, and posterior acoustic enhancement. On mammography, phyllodes tumors were $>3$ $\mathrm{cm}$, irregular in shape, with microlobulated margins, and exhibited higher density. On ultrasound, phyllodes tumors had irregular shape, varied margins, heterogenous echogenicity, and posterior acoustic enhancement. On MRI, fibroadenomas demonstrated a type I enhancement curve with hypointense internal septations while phyllodes tumors were associated with internal cystic areas. No other significant differences were noted [31].

Primary breast cancer: The most important differential diagnosis to exclude is that of primary breast malignancy. Most breast cancers display concerning characteristics such as irregular shape, ill-defined or spiculated margins, and fine pleomorphic/linear calcifications, as described in the BIRADS lexicon. However, 10-20\% of primary breast malignancies can present as well-circumscribed masses [32].

Triple negative breast cancer (absence of estrogen receptors, progesterone receptors, and the HER2/neu gene) does not exhibit the typical features of a primary breast malignancy. In a review of imaging triple negative breast cancers, Dogan and Turnball (2012) discussed such differences [33]. On mammography, they commonly present as a circumscribed mass in up to $24 \%$ of cases and often without calcifications. On ultrasound, they can appear as wellcircumscribed masses with posterior acoustic enhancement, possibly due to tumoral necrosis. On MRI, a rim enhancement pattern was seen in $76 \%$ of cases and other features included smooth margins, high intra-tumoral T2 signal, and a persistent enhancement pattern.

Additional well-circumscribed round/oval primary breast malignancies with smooth margins include invasive mammary carcinoma subtypes (such as intracystic papillary carcinoma), invasive papillary carcinoma, mucinous carcinoma, and medullary carcinoma [32]. MRI is vital in evaluating these malignancies as they demonstrate a type III (washout) enhancement pattern. Notably, mucinous carcinomas can be seen exhibiting a type I enhancement pattern [32].

\section{Conclusion:}

Breast plasmacytoma is an uncommon entity that should be considered in patients with multiple myeloma presenting with a new palpable breast mass. The mass should be evaluated with breast imaging modalities, primarily mammogram and ultrasound. There is a broad differential that can mimic breast plasmacytoma, which includes hematoma, infection, fibroadenoma/phyllodes tumor, and primary breast cancer. Biopsy is ultimately the gold standard for diagnosis as primary breast cancer must be excluded. Overall, prognosis for extramedullary plasmacytomas is poor with limited treatment options including radiotherapy and surgical excision.

\section{TEACHING POINT}

In patients with a history of multiple myeloma presenting with a palpable breast mass, breast plasmacytoma should be included in the differential diagnosis and further worked up with dedicated breast imaging (mammography, US, and MRI if needed). Generally, imaging will show round or oval wellcircumscribed vascular masses, in which a biopsy should be considered to rule out primary breast malignancy and guide treatment.

\section{REFERENCES}

1. Blade J, Fernandez de Larrea C, Rosinol L, Cibeira MT, Jimenez R, Powles R. Soft-tissue plasmacytomas in multiple myeloma: incidence, mechanisms of extramedullary spread, and treatment approach. J Clin Oncol. 2011;29(28):3805-12. PMID: 21900099.

2. Shui C, Hong-Gang K, Yan-Xue L, Xiu-Bao R. Synchronous infiltrating ductal carcinoma and primary extramedullary plasmacytoma of the breast. World Surg Oncol. 2009;7(43):1-3. PMID: 19393076.

3. Kalyani A, Rohaizak M, Cheong SK, Nor Aini U, Balasundaram V, Norlia A. Recurrent multiple myeloma presenting as a breast plasmacytoma. Med $\mathrm{J}$ Malaysia. 2010;65(30):227-8. PMID: 21939175.

4. Stawis AN, Maennie D, Festuccia M, Uddin Z, Bruno B. Recurrent plasmacytomas after allografting in a patient with multiple myeloma. Case Rep Med. 2012. PMID: 23326271. 
5. Karan B, Pourbagher A, Bolat FA. Unusual malignant breast lesions: imaging-pathological correlations. Diagn Interv Radiol. 2012;18(3):270-6. PMID: 21948695.

6. Hussain, A, Singh M, Singh K, Bagga H. Multiple extramedullary plasmacytoma with lytic bony lesions: a rare case report. Case Rep Med. 2013. PMID: 23476660

7. Majadob K, Al-Sakkaf W, Rezk F, Zegocki K, Al-Refaie F. Recurrence of extramedullary plasmacytoma of the breast. Ecancermedicalscience. 2013;7:322. PMID: 23781277.

8. Ancochea A, Sanchez-Gonzalez B, Maiques JM, Abella E. Breast plasmacytoma in a male patient. Med Clin. 2014;143(11):515-6. PMID: 24581842.

9. Neuhaus T, Hess T. Bilateral extramedullary plasmacytoma of the breast. Breast J. 2014;20(3):315-8. PMID: 24673829.

10. Lee HS, Kim JY, Kang CS, Kim SH, Kang JH. Imaging features of bilateral breast plasmacytoma as unusual initial presentation of multiple myeloma: case report and literature review. Acta Radiol Short Rep. 2014;3(10). PMID: 25535570.

11. Low SF, Mohd Tap NH, Kew TY, Ngiu CS, Sridharan R. Non-secretory multiple myeloma with extensive extramedullary plasmacytoma: a diagnostic dilemma. Iran $\mathbf{J}$ Radiol. 2015;12(3):e11760. PMID: 26528383.

12. Fischer TR, Higashi F, Crusoe Ede Q, Hungria VT. Bilateral breast plasmacytoma: a clinical case report. Rev Bras Hematol Hemoter. 2016;38(2):166-9. PMID: 27208578.

13. Park YM. Imaging findings of plasmacytoma of both breasts as a preceding manifestation of multiple myeloma. Case Rep Med. 2016. PMID: 26925106.

14. Aagre S, Madabhavi I, Patel A, Anand A, Panchal H, Parikh S. Primary plurifocal extramedullary plasmacytoma of breast. Breast J. 2016;22(4):465-466. PMID: 27059937.

15. Alsadi A, Lin D, Alnajar H, Brickman A, Martyn C, Gattuso P. Hematologic malignancies discovered on investigation of breast abnormalities. South Med J. 2017;110(10):614-20. PMID: 28973700.

16. Wienbeck S, Meyer HJ, Uhlig J, et al. Radiological imaging characteristics of intramammary hematological malignancies: results from a german multicenter study. Sci Rep. 2017;7(1):7435. PMID: 28785116.

17. Le DK, Metter D, Krause JR. Plasmablastic plasmacytoma of the breast. Proc. 2017;30(2):203-4. PMID: 28485083.

18. Orguc S, Akin M, Aydogdu I, Nese N. Bilateral plasmacytoma of the breast. Breast J. 2018;24(2):210-211. PMID: 28805290.

19. Jawahar A, Nagamine A, Gamez R. Breast plasmacytoma with associated amyloidosis mimicking breast carcinoma. Breast J. 2018;24(6):1071-73. PMID: 30255602.
20. Urano M, Denewar FA, Okabe R, et al. Relapsed multiple myeloma manifesting as extramedullary plasmacytoma of the breast: Imaging findings. Radiol Case Rep. 2019;14(5):584587. PMID: 30891107.

21. Hoang JT, Yang R, Shah ZA, Spigel JJ, Pippen JE. Clinico-radiologic features and management of hematological tumors in the breast: a case series. Breast Cancer. 2019;26(2):244-248. PMID: 30229499.

22. Beydoun AS, Ovalle F, Brannock K, Gobble RM. A case report of a breast implant-associated plasmacytoma and literature review of non-ALCL breast implant-associated neoplasms. Aesthet Surg J. 2019;39(7):N234-239. PMID: 30475976.

23. Surov A, Holzhausen HJ, Ruschke K, Arnold D, Spielmann RP. Breast plasmacytoma. Acta Radiol. 2010;51(5):498-504. PMID: 20429767.

24. Kim EE, Sawwaf ZW, Sneigej N. Multiple myeloma of the breast: magnetic resonance and ultrasound imaging findings. Breast Disease. 1996;9(4):229-33.

25. Lamy $\mathrm{O}$, von Bremen $\mathrm{K}$, Burckhardt $\mathrm{P}$. Breast plasmacytoma. Leuk Lymphoma. 2000;37(5-6):611-5. PMID: 11042522 .

26. Touzeau C, Moreau P. How I treat extramedullary myeloma. Blood. 2016;127(8):971-6. PMID: 26679866.

27. Pour L, Sevcikova S, Greslikova H, et al. Soft-tissue extramedullary multiple myeloma prognosis is significantly worse in comparison to bone-related extramedullary relapse. Haematologica.2014;99(2):360-64. PMID: 24038024

28. Mateos MV, Ludwig H, Bazarbachi A, et al. Insights on multiple myeloma treatment strategies. Hemasphere. 2019;3(1):e163. PMID: 31723802.

29. Wen G, Wang W, Zhang Y, Niu S, Li Q, Li Y. Management of extramedullary plasmacytoma: role of radiotherapy and prognostic factor analysis in 55 patients. Chin J Cancer Res. 2017;29(5):438-446. PMID: 29142463.

30. Leong PW, Chotai NC, Kulkarni S. Imaging features of inflammatory breast disorders: a pictorial essay. Korean J Radiol. 2018;19(1):5-14. PMID: 29353994

31. Duman L, Gezer NS, Balci P, et al. Differentiation between phyllodes tumors and fibroadenomas based on mammographic sonographic and MRI features. Breast Care (Basel). 2016;11(2):123-7. PMID: 27239174.

32. Yoo JL, Woo OH, Kim YK, et al. Can MR imaging contribute in characterizing well-circumscribed breast carcinomas? Radiographics. 2010;30(6):1689-702. PMID: 21071383

33. Dogan BE, Turnbull LW. Imaging of triple-negative breast cancer. Ann Oncol. 2012;23(6):23-9. PMID: 23012298 


\section{FIGURES}

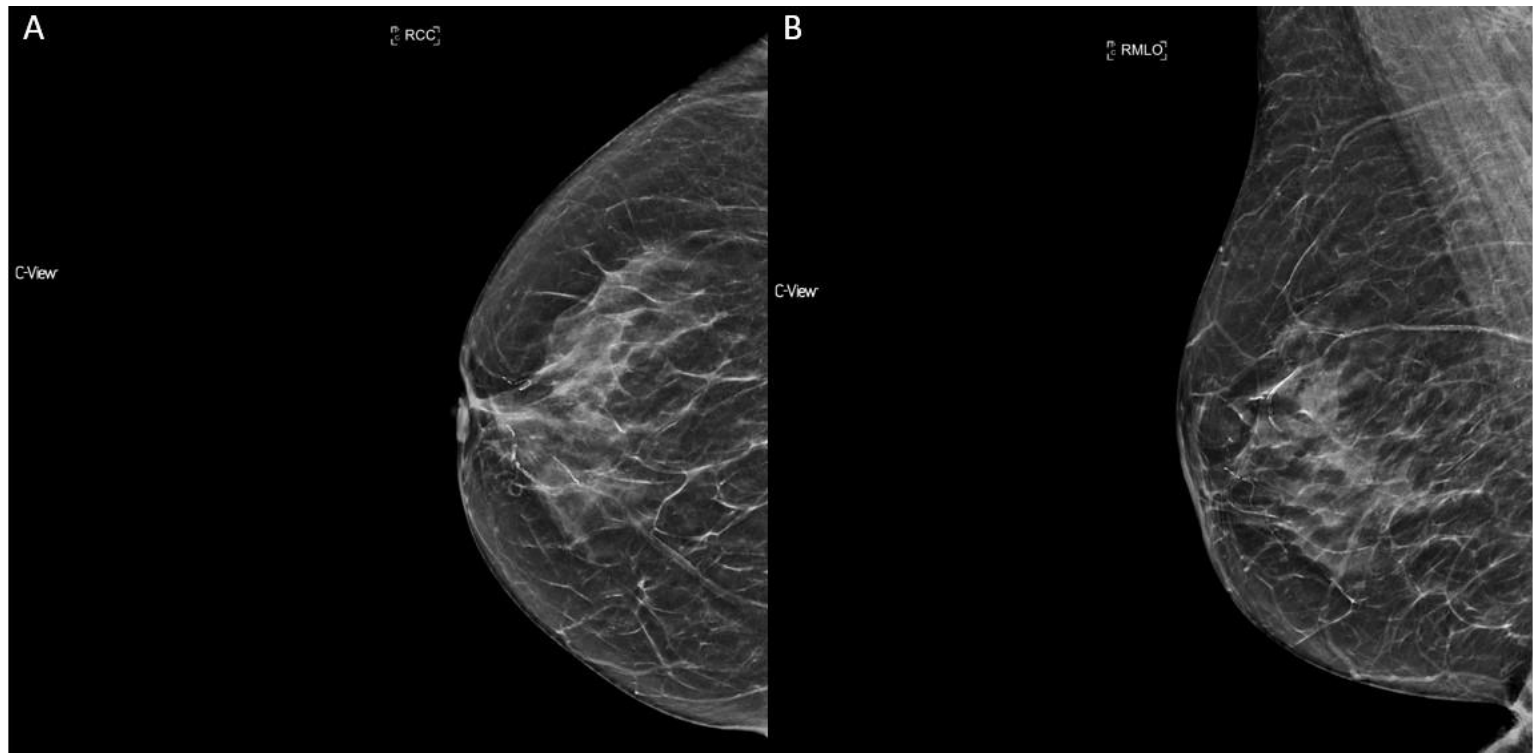

Figure 1: 74-year-old woman with multiple myeloma presenting with a palpable right breast, consistent with biopsy proven breast plasmacytoma. Screening mammogram of the right breast with craniocaudal and mediolateral oblique views four months prior to discovery of a palpable right breast mass.

Findings: A and B: Heterogeneously dense breast parenchyma. No suspicious dominant masses, suspicious microcalcifications, or areas of architectural distortion. BIRADS Category 1 - Negative.

Technique: Hologic Detector. $30 \mathrm{kVp}, 57 \mathrm{mAs}$, thickness $46 \mathrm{~mm}$. A: Craniocaudal view, angle 0 degrees. B: Mediolateral Oblique view, angle 45 degrees.

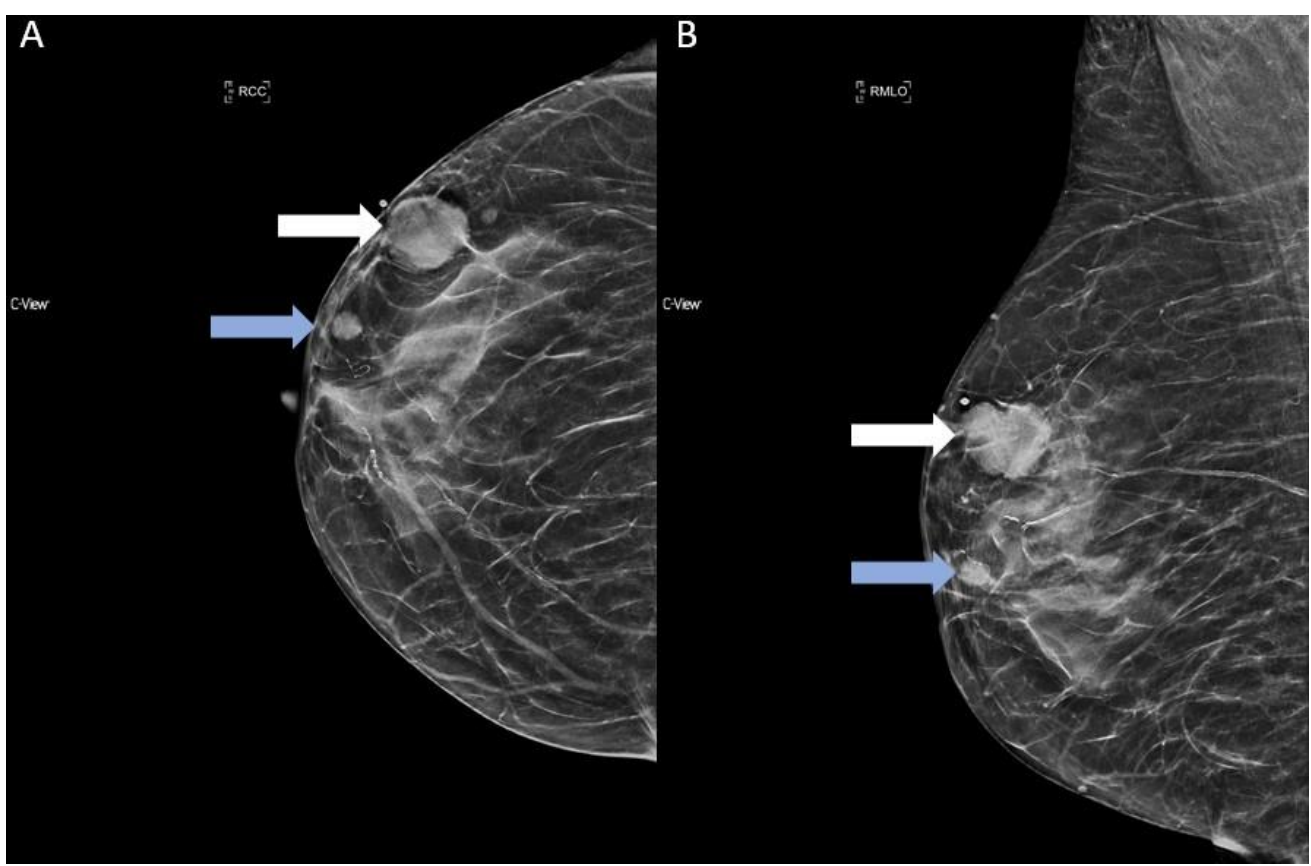

Figure 2: 74-year-old woman with multiple myeloma presenting with a palpable right breast mass, consistent with biopsy proven breast plasmacytoma. Diagnostic mammogram of the right breast with craniocaudal and mediolateral oblique views.

Findings: A and B: New $2.1 \times 1.9 \times 1.8 \mathrm{~cm}$ round well-circumscribed hyperdensity within the right upper outer quadrant in the middle third (white arrows). New $0.8 \times 0.7 \times 0.5 \mathrm{~cm}$ round well-circumscribed hyperdensity within the right upper outer quadrant in the anterior third of the breast (blue arrows). No suspicious calcifications, nipple retraction, skin thickening, or areas of architectural distortion. BI-RADS 0 - Incomplete, requiring additional imaging.

Technique: Hologic Detector. $30 \mathrm{kVp}, 57 \mathrm{mAs}$, thickness $46 \mathrm{~mm}$. A: Craniocaudal view, angle 0 degrees. B: Mediolateral Oblique view, angle 45 degrees. 


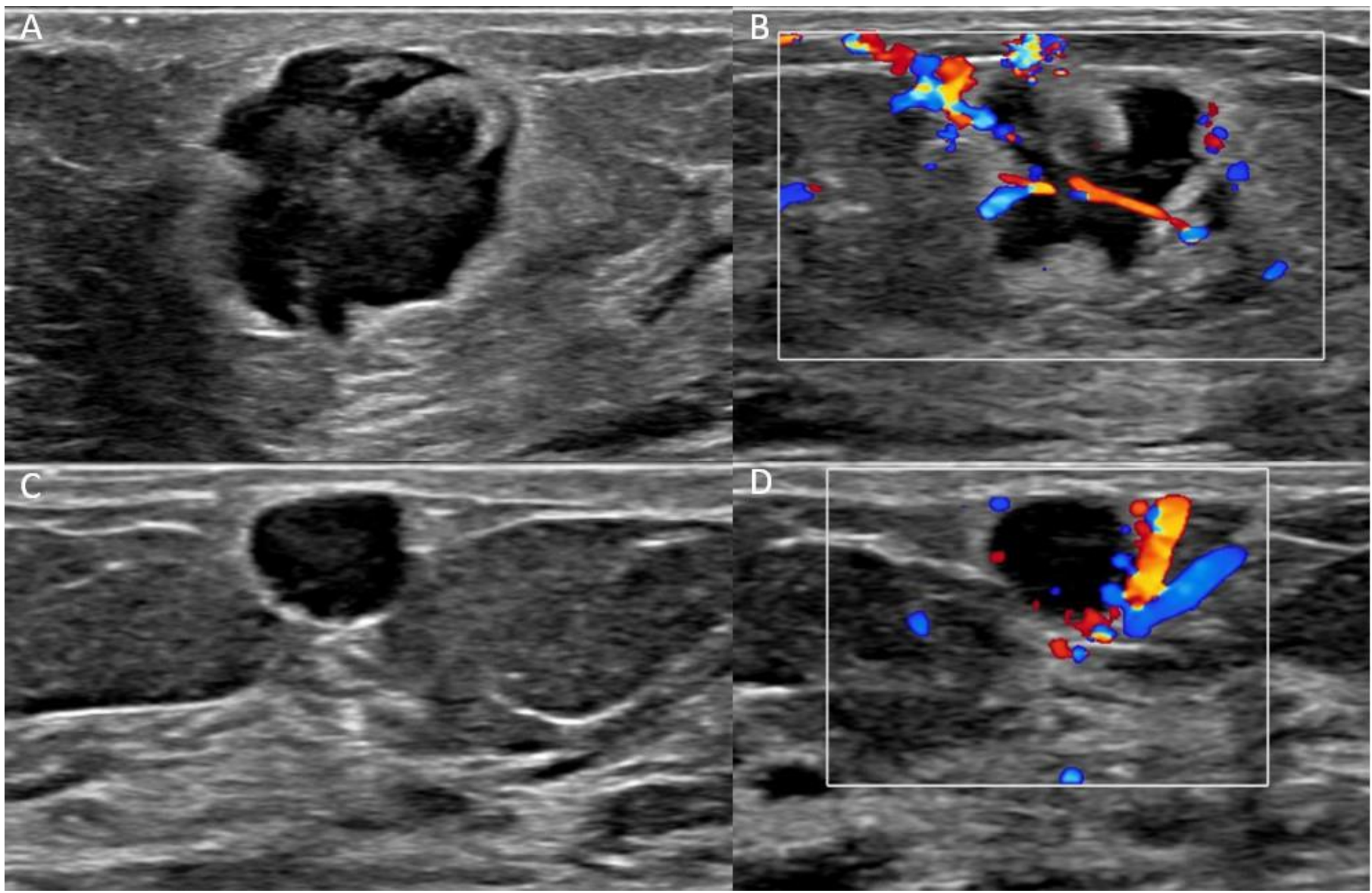

Figure 3: 74-year-old woman with multiple myeloma presenting with a palpable right breast mass, consistent with biopsy proven breast plasmacytoma. Ultrasound of the right breast following diagnostic mammogram.

Findings: A and B: $2.4 \times 1.4 \times 1.8 \mathrm{~cm}$ mixed-echogenic mass at the 10:00 position $5 \mathrm{~cm}$ from the nipple with surrounding increased vascularity. C and D: $0.6 \times 0.8 \times 0.6 \mathrm{~cm}$ hypoechoic mass with indistinct margins at the 9:00 position $3 \mathrm{~cm}$ from the nipple. BIRADS 4 - suspicious abnormality and biopsy should be considered.

Technique: EPIQ ultrasound station, linear array transducer $10 \mathrm{MHz}$ with a depth of $2.5 \mathrm{~cm}$. 


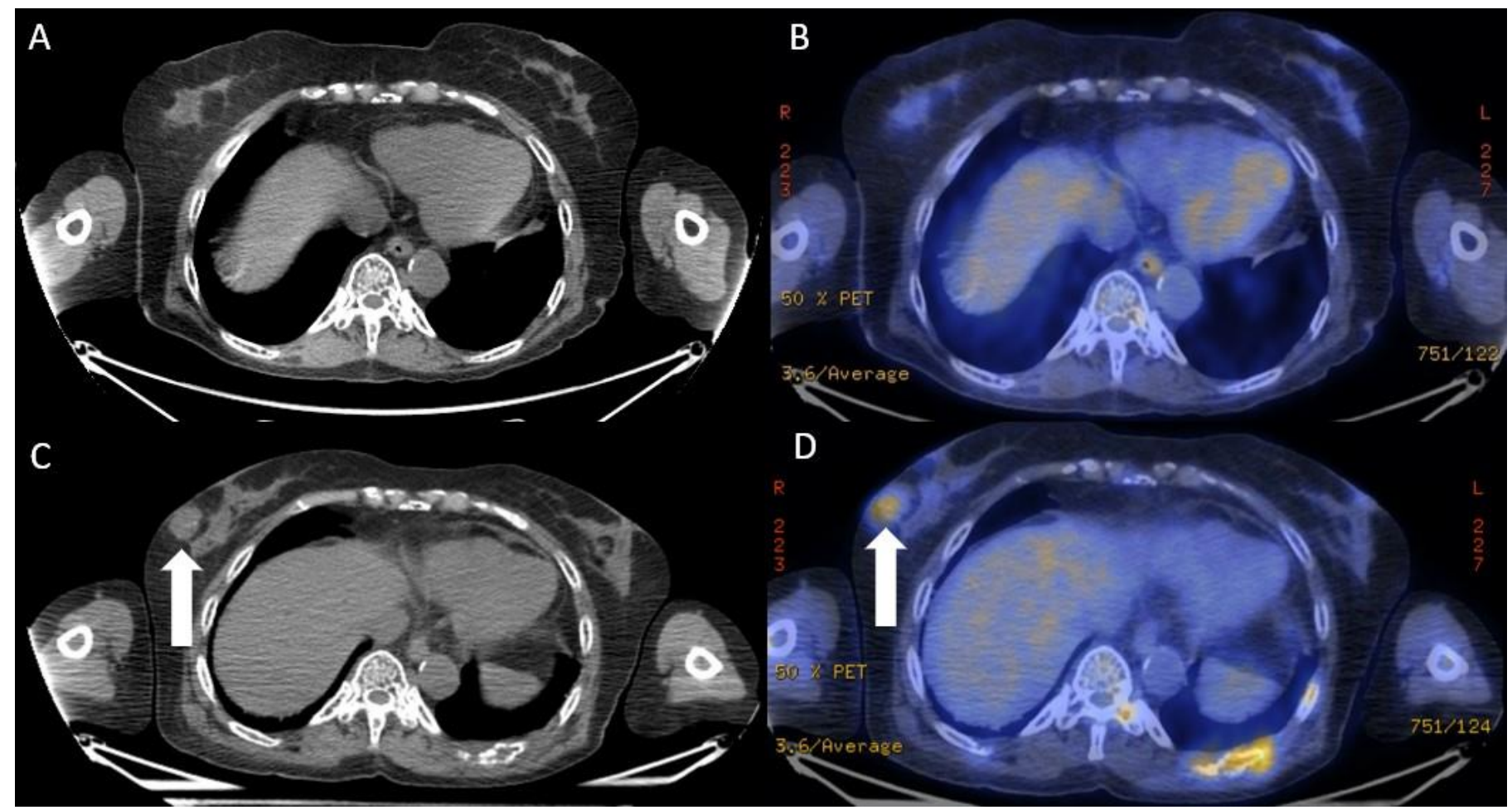

Figure 4: 74-year-old woman with multiple myeloma presenting with a palpable right breast mass, consistent with biopsy proven breast plasmacytoma. A and B: Whole-body fluorodeoxyglucose (FDG) positron emission tomography/computed tomography (PET/CT) completed one year prior to discovery of a palpable right breast mass. C and D: Whole-body PET/CT completed after biopsy of right breast plasmacytoma.

Findings: A and B: No soft tissue density or FDG avid mass in the right breast. C and D: Interval development of a right breast mass lateral to the nipple measuring $2.3 \times 1.8 \mathrm{~cm}$ with soft tissue density on nonenhanced CT and demonstrating a SUV maximum of $3.6 \mathrm{~g} / \mathrm{mL}$. Innumerable FDG avid osseous lesions through the axial and appendicular skeleton, such as a partially visualized FDG-avid lesion in the left ninth posterior rib.

Technique: Discovery PET/CT 690. Non-contrast spiral CT was performed for patient positioning and attenuation correction. Then, FDG PET/CT was performed from the vertex to the feet with a slice thickness $3.75 \mathrm{~mm}$. Fused FDG images were reconstructed on a separate workstation. A and B: After IV injection of $10.81 \mathrm{mCi}$ F-18 FDG, the patient rested for 64 minutes. C and D: After IV injection of $10.87 \mathrm{mCi}$ F-18 FDG, the patient rested for 59 minutes. 


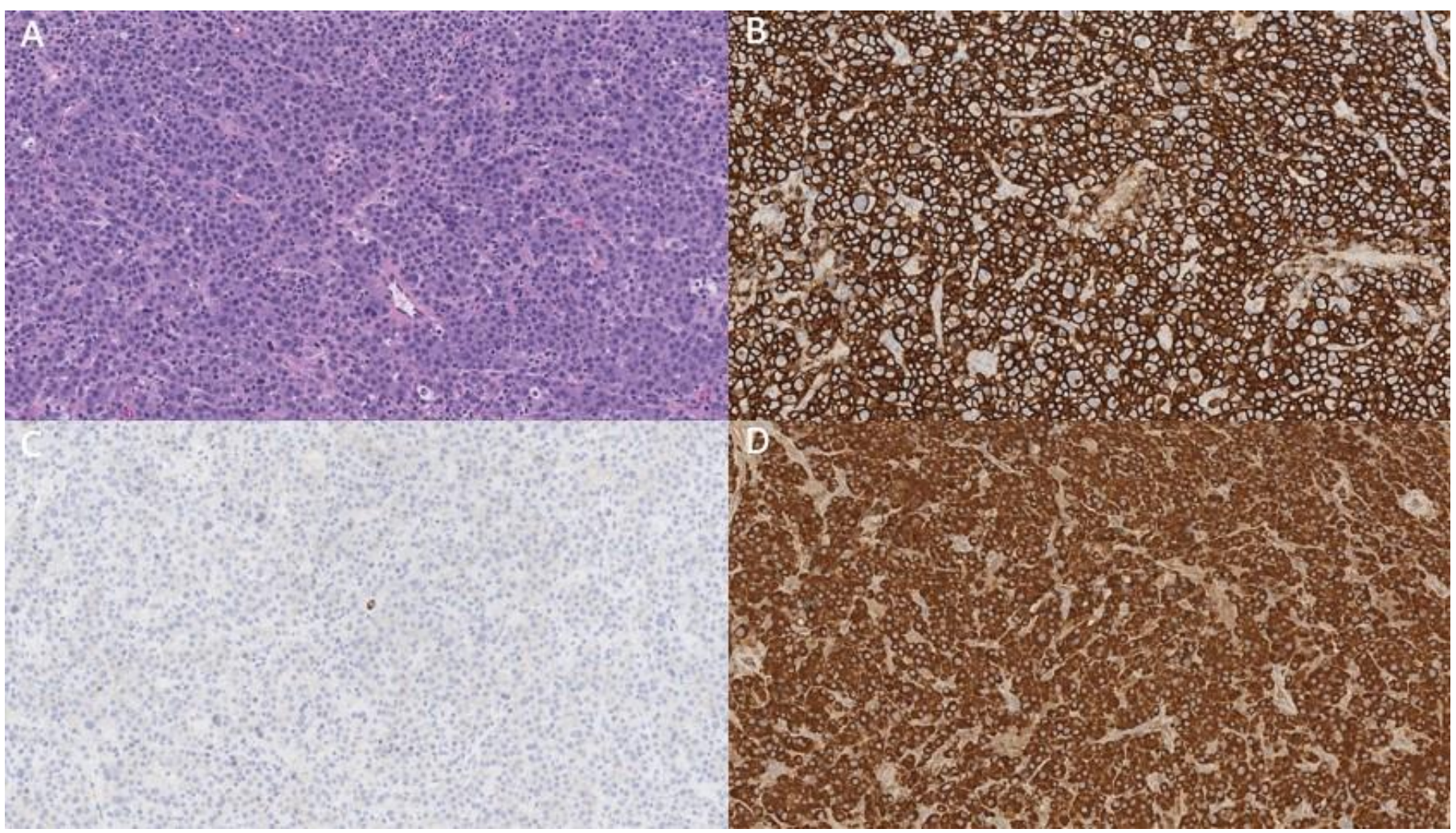

Figure 5: 74-year-old woman with multiple myeloma presenting with a palpable right breast mass, consistent with biopsy proven breast plasmacytoma. Histologic findings of ultrasound guided right breast mass biopsy.

Findings: A: H\&E staining shows hypercellular sheet of cells with a plasma cell appearance (eccentric nuclei with "clock-face" chromatin, place cytoplasm, and perinuclear clearing). B: CD138 staining shows strong diffuse positivity confirming the presence of plasma cell differentiation. C: Kappa staining shows only rare positive cells. D: Lambda staining shows extensive positive cells. Taken together, the Kappa and Lambda staining demonstrate that the plasma cells are monoclonal and lambda-restricted.

Technique: A: H\&E stain at 200x magnification. B: CD138 immunohistochemical stain at 200x magnification. C: Kappa immunohistochemical stain at 200x magnification. D: Lambda immunohistochemical stain at $200 \mathrm{x}$ magnification. 


\begin{tabular}{|c|c|}
\hline Etiology & $\begin{array}{l}\text { - Plasmacytomas are tumors resulting from plasma cell dyscrasias, occurring as single lesions or in the setting of } \\
\text { multiple myeloma. When they occur in soft tissues, they are known as extramedullary plasmacytomas. }\end{array}$ \\
\hline Incidence & $\begin{array}{l}\text { - Extramedullary plasmacytomas in the setting of multiple myeloma occur between } 7-18 \% \text { of cases, with up to } \\
80 \% \text { involving the upper aerodigestive tract. } \\
\text { - Extramedullary involvement of the breast is rare and can occur both in the absence or presence of multiple } \\
\text { myeloma. In total, } 83 \text { published reports have been found in the literature spanning } 1928 \text { to } 2019 \text {. }\end{array}$ \\
\hline $\begin{array}{l}\text { Gender } \\
\text { Ratio }\end{array}$ & $\begin{array}{l}\text { - Extramedullary plasmacytoma of the breast are seen almost exclusively in women, with only one case report } \\
\text { involving the male gender. }\end{array}$ \\
\hline $\begin{array}{l}\text { Age \& Risk } \\
\text { Factors }\end{array}$ & $\begin{array}{l}\text { - No definite age predilection for the development of extramedullary plasmacytoma of the breast. The median } \\
\text { age for development of multiple myeloma is 66-70 years old. } \\
\text { - No study has evaluated risk factors for development of breast plasmacytomas. However, those at risk for } \\
\text { plasma cell dyscrasias (e.g., advanced age, African American ethnicity, family history of disease) are likely at } \\
\text { higher risk. }\end{array}$ \\
\hline Trea & $\begin{array}{l}\text { - Treatment for extramedullary plasmacytoma of the breast involves radiotherapy and possibly surgical } \\
\text { excision. } \\
\text { - It is also necessary to address/treat the underlying plasma cell dyscrasia. In the case of multiple myeloma, this } \\
\text { can include chemotherapy, radiotherapy, and autologous stem cell transplant. }\end{array}$ \\
\hline Prognosis & $\begin{array}{l}\text { - Overall prognosis for extramedullary plasmacytoma is poor. In the setting of multiple myeloma, overall } \\
\text { survival rate can be as low as four months. } \\
\text { Primary breast plasmacytomas have been shown to have a better prognosis than those associated with multiple } \\
\text { myeloma. }\end{array}$ \\
\hline $\begin{array}{l}\text { Imaging } \\
\text { Findings }\end{array}$ & $\begin{array}{l}\text { - Mammography: Oval/round well-circumscribed hyperdense mass. } \\
\text { - Ultrasound: Oval/round heterogenous to hypoechoic vascular mass. } \\
\text { - CT: Oval/round homogenously enhancing mass. } \\
\text { - MRI: Oval/round mass with T1 low to isointense signal, T2 intermediate to hyperintense signal, massive } \\
\text { homogenous enhancement, and delayed washout kinetics. } \\
\text { - PET/CT: Oval/round FDG avid mass. }\end{array}$ \\
\hline
\end{tabular}

Table 1: Summary table of extramedullary plasmacytoma of the breast. 


\begin{tabular}{|c|c|c|c|}
\hline & Mammography & Ultrasound & MRI \\
\hline Plasmacytoma & $\begin{array}{l}\text { - Oval/round well- } \\
\text { circumscribed } \\
\text { hyperdense masses. } \\
\text { - No spiculations or } \\
\text { microcalcifications. }\end{array}$ & $\begin{array}{l}\text { - Oval/round, well-defined or } \\
\text { indistinct margins, hypoechoic } \\
\text { to heterogenous. } \\
\text { - Color flow present. }\end{array}$ & $\begin{array}{l}\text { - T1: Low to isointense signal intensity. } \\
\text { - T2: Intermediate to high signal intensity. } \\
\text { - Homogenous massive enhancement with } \\
\text { delayed washout kinetics (type III } \\
\text { enhancement curve). }\end{array}$ \\
\hline Hematoma & $\begin{array}{l}\text { - Variable shape/margin } \\
\text { and can appear mass- } \\
\text { like. } \\
\text { - Hyperdense mass. }\end{array}$ & $\begin{array}{l}\text { - Variable shape/margin. } \\
\text { - Anechoic to hypoechoic } \\
\text { depending on acuity. } \\
\text { - Avascular. }\end{array}$ & $\begin{array}{l}\text { - Variable T1, which is hyperintense in the } \\
\text { acute setting. Dependent on age of blood } \\
\text { products. } \\
\text { - No significant enhancement. Uniformly } \\
\text { thin rim of enhancement with } \\
\text { postoperative hematoma. }\end{array}$ \\
\hline $\begin{array}{l}\text { Infection (breast } \\
\text { abscess) }\end{array}$ & $\begin{array}{l}\text { - Variable shape/margin. } \\
\text { - Can appear mass-like } \\
\text { and hyperdense. } \\
\text { - Diffuse edema and skin } \\
\text { thickening. }\end{array}$ & $\begin{array}{l}\text { - Thick-walled hypoechoic fluid } \\
\text { collection with internal debris. } \\
\text { - Peripheral vascularity. } \\
\text { - Adjacent skin } \\
\text { thickening/edema. }\end{array}$ & $\begin{array}{l}\text { - Avid rim enhancing fluid collection on } \\
\text { T1 post contrast imaging. } \\
\text { - Skin thickening. }\end{array}$ \\
\hline Fibroadenoma & $\begin{array}{l}\text { - }<3 \mathrm{~cm} \text { in size. } \\
\text { - Oval well- } \\
\text { circumscribed } \\
\text { hyperdense mass. }\end{array}$ & $\begin{array}{l}\text { - Oval well-circumscribed } \\
\text { parallel hypoechoic mass with } \\
\text { posterior acoustic } \\
\text { enhancement. } \\
\text { - Color flow present. }\end{array}$ & $\begin{array}{l}\text { - T1 hypo/iso-intense and variable T2. } \\
\text { - Progressive enhancement (type I } \\
\text { enhancement curve). } \\
\text { - Hypointense internal septations. }\end{array}$ \\
\hline $\begin{array}{l}\text { Phyllodes } \\
\text { Tumor }\end{array}$ & $\begin{array}{l}\text { - }>3 \mathrm{~cm} \text { in size. } \\
\text { - Irregular, indistinct or } \\
\text { microlobulated margins. } \\
\text { Hyperdense mass. }\end{array}$ & $\begin{array}{l}\text { - Irregular shape, varied } \\
\text { margins, heterogenous } \\
\text { echogenicity, posterior } \\
\text { acoustic enhancement. } \\
\text { - Color flow present. }\end{array}$ & $\begin{array}{l}\text { - T1 hypo/iso-intense and variable T2. } \\
\text { - Variable enhancement pattern. } \\
\text { - Internal cystic areas. }\end{array}$ \\
\hline $\begin{array}{l}\text { Triple negative } \\
\text { breast cancer. } \\
\text { Also consider } \\
\text { invasive } \\
\text { mammary } \\
\text { carcinoma } \\
\text { subtypes. }\end{array}$ & $\begin{array}{l}\text { - Well-circumscribed } \\
\text { mass, which can be } \\
\text { hyperdense. } \\
\text { - Calcifications: Often } \\
\text { absent in triple negative } \\
\text { breast cancer. }\end{array}$ & $\begin{array}{l}\text { - Oval/round well- } \\
\text { circumscribed hypoechoic } \\
\text { mass with posterior acoustic } \\
\text { enhancement. } \\
\text { - Color flow present. }\end{array}$ & $\begin{array}{l}\text { - Well-circumscribed mass with high T2 } \\
\text { intra-tumoral signal. } \\
\text { - Often with type III (washout) } \\
\text { enhancement pattern. }\end{array}$ \\
\hline
\end{tabular}

Table 2: Differential diagnosis table for hyperdense breast masses.

\section{ABBREVIATIONS}

CT $=$ Computed Tomography

FDG PET/CT = Fluorodeoxyglucose positron emission tomography/computed tomography

MRI = Magnetic Resonance Imaging

SUV = Standardized Uptake Value

US = Ultrasound

\section{KEYWORDS}

Plasmacytoma; breast; multiple myeloma; mammography; ultrasound

\section{Online access}

This publication is online available at: www.radiologycases.com/index.php/radiologycases/article/view/4110

\section{Peer discussion}

Discuss this manuscript in our protected discussion forum at: www.radiolopolis.com/forums/JRCR

\section{Interactivity}

This publication is available as an interactive article with scroll, window/level, magnify and more features. Available online at www.RadiologyCases.com

\section{Published by EduRad

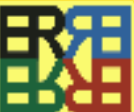 \\ www.EduRad.org}

